\title{
UJI DENSITAS DAN POROSITAS SERTA KARAKTERISASI MENGGUNAKAN XRD DAERAH MATA AIR PANAS SEMURUP SUNGAI MEDANG KABUPATEN KERINCI PROVINSI JAMBI
}

\author{
Larlen Nixolas ${ }^{1^{*}}$, Nova Susanti ${ }^{2}$, Samsidar $^{1}$, Linda Handayani ${ }^{1}$ \\ ${ }^{1}$ Program Studi Fisika, \\ Fakultas Sains dan Teknologi, \\ ${ }^{2}$ Program Studi Pendidikan Fisika, \\ Fakultas Keguruan dan Ilmu Pendidikan, \\ Universitas Jambi, Mendalo Darat Jambi 36361 \\ *E-mail: larlennixolas1@gmail.com
}

\begin{abstract}
Test Density and Porosity of rock have been done to see the relation to temperature influence $100{ }^{\circ} \mathrm{C}, 200^{\circ} \mathrm{C}$ and $300{ }^{\circ} \mathrm{C}$. Rocks that will be tested first heated temperature with furnace tool then weighed with a digital balance. Density and Porosity measurement data were analyzed using Matlab Software with ASTMC373 equation. The result of Matlab in the form of graph shows average temperature change to Semurup rock density of $0.03 \mathrm{~g} / \mathrm{cm} 3$ and the effect of temperature on Semurup rock porosity at $300{ }^{\circ} \mathrm{C}$ is $30.29 \%$. The average temperature change to Medang River rock density is $0.003 \mathrm{~g} / \mathrm{cm} 3$ and the effect of temperature on Medang River rock porosity at $300{ }^{\circ} \mathrm{C}$ is $0,55 \%$. Looking at the rock crystal structure used XRD. Data from Characterization using XRD was analyzed with High Score Plus software. The result of rock characterization using XRD, from semurup showed that component of CaCO3 is 94\%, crystal structure not yet fully formed and still in amorphous form, meanwhile rock from medang river show that component of CaCO3 is with $98 \%$, crystalline structure have formed crystal.
\end{abstract}

Keywords: density, porosity, temperature, XRD.

\begin{abstract}
ABSTRAK
Uji Densitas dan Porositas batuan telah dilakukan untuk melihat hubungan terhadap pengaruh temperatur 100 ${ }^{\circ} \mathrm{C}, 200{ }^{\circ} \mathrm{C}$ dan $300{ }^{\circ} \mathrm{C}$. Batuan yang akan di uji terlebih dahulu diberi pemanasan temperatur dengan alat furnace lalu ditimbang dengan Neraca digital. Data pengukuran Densitas dan Porositas dianalisis menggunkan Software Matlab dengan persamaan ASTMC373. Hasil Matlab berupa grafik menunjukan rata-rata perubahan temperatur terhadap densitas batuan Semurup sebesar $0,03 \mathrm{~g} / \mathrm{cm}^{3}$ dan pengaruh temperatur terhadap Porositas batuan Semurup pada suhu $300{ }^{\circ} \mathrm{C}$ adalah 30,29\%. Rata-rata perubahan temperatur terhadap densitas batuan Sungai Medang sebesar $0,003 \mathrm{~g} / \mathrm{cm}^{3}$ dan pengaruh temperatur terhadap Porositas batuan Sungai Medang pada suhu $300{ }^{\circ} \mathrm{C}$ adalah 0,55\%. Melihat struktur kristal batuan digunakan XRD. Data dari Karakterisasi menggunakan XRD dianalisis dengan software High Score Plus. Hasil karakterisasi batuan menggunakan $X R D$, dari semurup menunjukkan bahwa komponen $\mathrm{CaCO}_{3}$ adalah 94\%, struktur kristal belum terbentuk sempurna dan masih dalam bentuk amorf, sedangkan batuan dari sungai medang menunjukkan bahwa komponen $\mathrm{CaCO}_{3}$ adalah dengan $98 \%$, struktur kristal sudah terbentuk kristal.
\end{abstract}

Kata kunci: densitas, prositas, temperatur, XRD.

\section{PENDAHULUAN}

Mata air panas atau sumber mata air panas adalah tempat dimana keluar nya air tanah dari bawah bumi yang dipanaskan melalui panas bumi (geothermal) yang memiliki suhu lebih tinggi dari suhu air tanah disekitarnya. Penelitian tentang mata air panas didaerah kabupaten kerinci, pernah dilakukan oleh Yuliandini menununjukan bahwa daerah di sekitar sumber mata air panas tersebut tersusun atas batuan andesit dan batuan gamping [1].

Sifat fisik batuan berpengaruh terhadap adanya potensi panas bumi. Densitas batuan adalah massa partikel yang menempati suatu 
unit volume tertentu. Penelitian tentang densitas pernah dilakukan Iosifina (2017) bahwa densitas batuan alam yang didapatkan di atas permukaan relative kecil antara 0,2 $\mathrm{g} / \mathrm{cm}^{3}$ sampai $3.50 \mathrm{~g} / \mathrm{cm}^{3}$. Porositas merupakan sifat fisik batuan yang menunjukan kemampuan batuan untuk menampung fluida didalam pori-porinya.Berdasarkan porositas oleh BSN (Badan Standar Nasional) bahwa standard porositas batuan geothermal pada daerah terdapat mata air panas adalah rata-rata $11,168 \%$ sebagai sumber energi panas (geothermal) adalah 10\% [2].

Pada penelitian ini batuan diambil di daerah mata air panas semurup dan sungai medang, kabupaten kerinci, provinsi jambi. Batuan yang diambil dari mata air panas dilakukan uji sifat fisis dengan melihat pengaruh temperatur $100{ }^{\circ} \mathrm{C}, 200{ }^{\circ} \mathrm{C}$ dan 300 ${ }^{\circ} \mathrm{C}$. Batuan yang berasal dari batuan alam yang mengalami perubahan tekstur dan komposisi mineral pada fasa padat sebagai akibat perubahan kondisi fisika tekanan atau temperatur [3]. Akibat bertambahnya suhu batuan sebelumnya akan berubah sifat fisis seperti densitas dan porositas. X-ray Diffraction (XRD) adalah metode yang mampu menganalisis jenis dan sifat mineral pola difraksi yang dihasilkan. Di daerah mata air panas menunjukan bahwa batuan disekitar memiliki kandungan terbesar yaitu $\mathrm{SiO}_{2}$ (silica) dan Calsilit Karbonat $\left(\mathrm{CaCO}_{3}\right)$ [4]. Pada penelitian ini batuan dari daerah mata air panas semurup dan sungai medang akan karakterisasi XRD dan analisis digunakan software High Score Plus.

\section{METODE PENENELITIAN}

\section{Bahan penelitian}

Adapun alat yang digunakan dalam penelitian ini adalah gps, palu, gerinda, furnace, jaw crusher, pulverizer, ultasonik cleaner, sieving shake, gelas beker, neraca digital, spatula, furnace, dan sebagai alat karakterisasi digunakan $X$-ray
diffraction.Sedangkan bahan yang digunakan pada penelitian ini adalah batuan semurup, batuan sungai medang, larutan aceton, air mineral, amplas.

\section{Pengambilan sample}

Penelitian lapangan yang akan dilakukan, yaitu; survei secara langsung di lapangan kondisi fisik geologi daerah penelitian, mengambil sample dan memplot lokasi pengambilan sample pada peta lintasan berdasarkan data koordinat kontrol pada Global Position System (GPS). Batuan dari daerah panas bumi diambil dari 2 lokasi yang berbeda. Pengambilan sample batuan yang akan diambil berada di daerah semurup, sungai medang, kabupaten kerinci, Jambi.

\section{Preparasi sample}

Preparasi merupakan suatu rangkaian kegiatan penelitian dalam mempersiapkan batuan untuk di analisis, yang metodenya disesuaikan dengan bentuk batuan dan apa yang akan dianalisis [5]. Berdasarkan bentuk batuan yang akan dianalisis, terdapat 2 jenis preparasi yaitu berbentuk persegi 4 batuan dan dalam bentuk sample serbuk.

\section{Preparasi sample sifat fisis}

Batuan dipotong persegi 4 (empat) sebanyak 4 potong bagian yang kemudian dihaluskan dan diratakan mengunakan amplas. Setelah rata dan halus, batuan di ultasonik cleaner dengan larutan acetone $20 \%+80 \%$ air mineral untuk mendapatkan parameter batuan yang akan diukur bersih dari lumut dan tanah yang menempel dibatuan. Selanjutnya batuan yang telah bersih dari lumut dan tanah tersebut di furnace dengan variasi temperatur $100{ }^{\circ} \mathrm{C}, 200{ }^{\circ} \mathrm{C}$ dan $300{ }^{\circ} \mathrm{C}$ selama 1 jam tiap temperatur yang diberikan. Kemudian batuan yang telah di furnaceakan dilakukan pengukuran sifat fisis (Densitas dan porositas) batuan [6]. 


\section{Preparasi sample XRD}

Batuan dihancurkan dengan mengunakan alat jaw crusher. Setelah hancur, batuan dihaluskan menggunakan alat Pulverizer. Selanjutnya, batuan yang telah halus perlu lolos ayakan 200 mess dengan mengunakan Sieving shake. Sample batuan yang telah lolos ayakan tersebut dimasukan kedalam plastik sample yang diberi label untuk di karakterisasi menggunakan XRD.

\section{Pengambilan data densitas dan porositas}

Pengukuran yang dilakukan untuk mendapatkan sifat fisis batuan seperti densitas dan porositas yang di berikan perlakuan temperatur $100{ }^{\circ} \mathrm{C}, 200{ }^{\circ} \mathrm{C}$ dan $300{ }^{\circ} \mathrm{C}$.Sample batuan yang telah di diberikan perlakuan temperatur dimasukan ke dalam plastik sample yang diberikan label. Batuan ditimbang satu persatu menggunkan neraca digital yang dikalibrasi untuk pengukuran sifat fisis batuan (Densitas dan Porositas)[7]. Data yang didapat ada 8 pada sample batuan semurup ada 4 dan pada sample batuan sungai medang ada 4 , data yang didapat adalah nilai $\rho$ air dalam botol, massa batuan didalam air dan massa + air.

\section{Pengambilan data karakterisasi XRD}

Pengukuran yang dilakukan untuk mendapatkan karakterisasi dari alat X-ray
Diffractometer dengan tipe PANalytical XPert3 Powder yang dalam bentuk serbuk sample batu pada batuan daerah semurup dan sungai medang. Data yang didapat akan terbaca pada monitor berupa grafik.

\section{Analisis data densitas dan porositas}

Pada penelitian ini digunakan analisis data sifat fisis batuan (Densitas, porositas) mengunakan Test standar ASTM C373-88 data berupa grafik menggunakan software MATLAB 2009 yang dilihat persamaan terhadap teori fisika yaitu gas ideal terhadap perubahan temperatur.

\section{Analisis data karakterisasi XRD}

Pada penelitian dengan menganalisis data dari hasil karakterisasi XRD digunakan aplikasi/software HighScore Plus. Data yang dianalisis yaitu fasa mineral batuan, unsur kandungan batuan pada sample serbuk batuan semurup dan sungai medang, kabupaten kerinci, jambi.

\section{HASIL DAN PEMBAHASAN}

Pengambilan data sifat fisis (densitas dan porositas) menggunakan neraca digital dengan gelas beker yang berisi air didalamnya.

Hasil Sifat Fisis Semurup:

\begin{tabular}{|c|c|c|c|c|c|c|}
\hline $\begin{array}{c}\text { Suhu } \\
(\mathrm{T})\end{array}$ & $\begin{array}{c}\text { Massa } \\
\text { awal }(\mathrm{g})\end{array}$ & $\begin{array}{c}\text { Massa setelah } \\
\text { suhu }(\mathrm{g})\end{array}$ & $\begin{array}{c}\text { Massa }+ \\
\text { Air }(\mathrm{g})\end{array}$ & $\begin{array}{c}\text { Volume } \\
\text { M-S }(0,01)\end{array}$ & $\begin{array}{c}\text { Densitas } \\
\left(\mathrm{g} / \mathrm{cm}^{3}\right)\end{array}$ & $\begin{array}{c}\text { Porositas } \\
(\%)\end{array}$ \\
\hline $100{ }^{\circ} \mathrm{C}$ & 6,37 & 6,776 & 7,756 & 7,746 & 0,874 & 12,65 \\
\hline $200{ }^{\circ} \mathrm{C}$ & 6,12 & 6,60 & 7,60 & 7,59 & 0,86 & 13,17 \\
\hline $300{ }^{\circ} \mathrm{C}$ & 3,12 & 4,382 & 6,268 & 6,272 & 0,69 & 30,29 \\
\hline
\end{tabular}

Hasil Sifat Fisis Sungai medang :

\begin{tabular}{|c|c|c|c|c|c|c|}
\hline $\begin{array}{c}\text { Suhu } \\
(\mathrm{T})\end{array}$ & $\begin{array}{c}\text { Massa } \\
\text { awal (g) }\end{array}$ & $\begin{array}{c}\text { Massa setelah } \\
\text { suhu (g) }\end{array}$ & $\begin{array}{c}\text { Massa }+ \\
\text { Air }(\mathrm{g})\end{array}$ & $\begin{array}{c}\text { Volume } \\
\text { M-S }(0,01)\end{array}$ & $\begin{array}{c}\text { Densitas } \\
\left(\mathrm{g} / \mathrm{cm}^{3}\right)\end{array}$ & Porositas (\%) \\
\hline $100^{\circ} \mathrm{C}$ & 9,68 & 9,86 & 9,90 & 9,89 & 0,9969 & 0,40 \\
\hline $200^{\circ} \mathrm{C}$ & 9,69 & 9,957 & 10 & 9,99 & 0,9966 & 0,43 \\
\hline $300^{\circ} \mathrm{C}$ & 9,76 & 10,118 & 10,174 & 10,164 & 0,9954 & 0,55 \\
\hline
\end{tabular}


Analisis sifat fisis (densitas dan porositas) Semurup

Densitas Batuan SemurupDari program Matlab dengan persamaan ASTM dibuatkan grafik densitas terhadap temperatur.Hasil uji denistas batuan batuan semurup terhadap perubahan temperatur dapat digambarkan pada Gambar 1. Dari Gambar 1 densitas batuan dari Semurup, dapat dilihat hasil nilai densitas (B) akan mengalami perubahan setelah pemberian temperatur adalah densitas semakin menurun yaitu pada temperatur rendah $100^{\circ} \mathrm{C}$ sebesar $0,874 \mathrm{~g} / \mathrm{cm}^{3}$, temperatur sedang $200^{\circ} \mathrm{c}$ sebesar $0,86 \mathrm{~g} / \mathrm{cm}^{3}$ dan temperatur tinggi $300^{\circ} \mathrm{C}$ sebesar $0,69 \mathrm{~g} / \mathrm{cm}^{3}$.

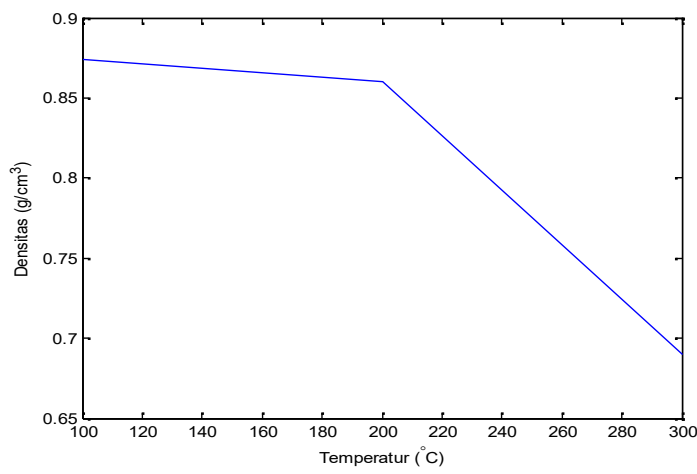

Gambar 1. Densitas Batuan Semurup Terhadap Temperatur.

Hasil dari penelitian yang telah dilakukan pada batuan Semurup dapat dianalisis bahwa densitas batuan sangat kecil dan mengalami perubahan setelah diberikan temperatur.Hasil uji porositas batuan semurup terhadap perubahan temperatur dapat digambarkan pada Gambar 2.

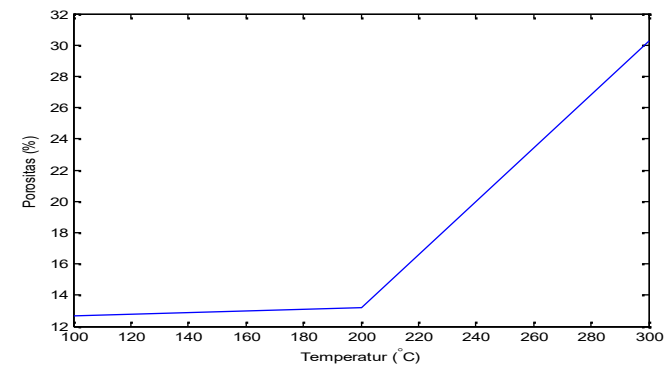

Gambar 2. Porositas Batuan Semurup Terhadap Temperatur.
Dari Gambar 2. Porositas batuan dari Semurup, dapat dilihat hasil nilai porositas $(\mathrm{P})$ akan mengalami perubahan setelah pemberian temperatur adalah porositas semakin membesar yaitu pada temperatur rendah $100^{\circ} \mathrm{C}$ sebesar $12,65 \%$, temperatur sedang $200^{\circ} \mathrm{C}$ sebesar $13,17 \%$, dan temperatur tinggi $300^{\circ} \mathrm{C}$ sebesar 30,29\% [8].

Dari hasil uji densitas dan porositas di daerah semurup yang telah dilakukan menunjukan bahwa densitas batuan sangat kecil dan setelah dilakukan pemberian temperatur rendah, sedang dan tinggi densitas tidak mengalami perubahan yang besar tetapi uji porositas didaerah semurup yang telah dilakukan menunjukan bahwa porositas batuan sangat besar dan setelah dilakukan pemberian temperatur rendah, sedang dan tinggi yang sangat besar adalah $30,29 \%$ pada suhu $300^{\circ} \mathrm{C}$.

\section{Analisis sifat fisis (densitas dan porositas) Sungai Medang}

Densitas Batuan Sungai medangdari program Matlab dengan persamaan ASTM dibuatkan grafik densitas terhadap temperatur.Hasil uji denistas batuan batuan sungai medang terhadap perubahan temperatur dapat digambarkan pada Gambar 3.

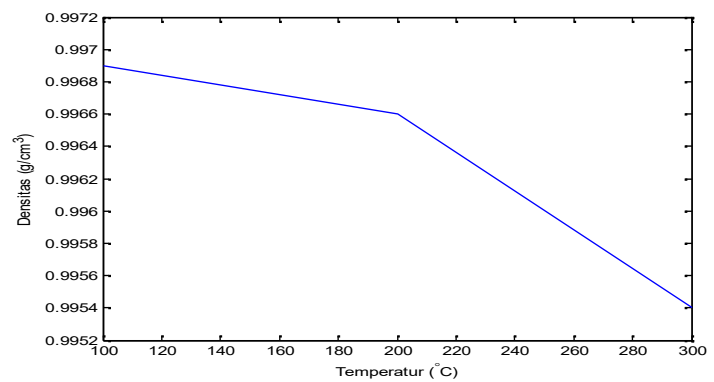

Gambar 3. Densitas Batuan Sungai Medang Terhadap Temperatur.

Dari Gambar 3. densitas batuan dari Sungai Medang, dapat dilihat hasil nilai densitas (B) akan mengalami perubahan setelah pemberian temperatur adalah densitas semakin menurun yaitu pada temperatur rendah $100^{\circ} \mathrm{c}$ sebesar $0,9969 \mathrm{~g} / \mathrm{cm}^{3}$, temperatur sedang $200^{\circ} \mathrm{C}$ sebesar $0,9966 \mathrm{~g} / \mathrm{cm}^{3}$ dan temperatur tinggi $300^{\circ} \mathrm{C}$ sebesar $0,995 \mathrm{~g} / \mathrm{cm}^{3}$. 
Dari hasil uji densitas batuan yang telah diberikan temperatur terlihat bahwa densitas batuan menurun tetapi tidak terlalu besar, yaitu $0,003 \mathrm{~g} / \mathrm{cm}^{3}$ sebab batuan sungai medang memiliki ciri khas yang keras dan memiliki kerapatan yang besar [9].

Hasil uji porositas batuan sungai medang terhadap perubahan temperatur dapat digambarkan pada Gambar 4.

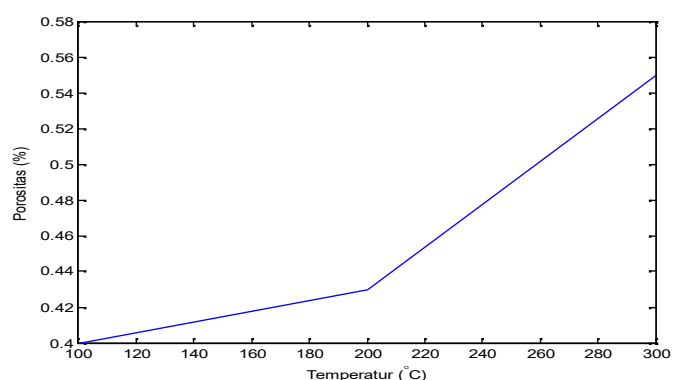

Gambar 4. Porositas Batuan Sungai Medang Terhadap Temperatur.

Dari Gambar 4. Porositas batuan dari Sungai medang, dapat dilihat hasil nilai porositas (P) akan mengalami perubahan setelah pemberian temperatur adalah porositas semakin membesar yaitu pada temperatur rendah $100^{\circ} \mathrm{c}$ sebesar $0.38 \%$, temperatur sedang $200^{\circ} \mathrm{C}$ sebesar $0.43 \%$, dan temperatur tinggi $300^{\circ} \mathrm{C}$ sebesar $0.55 \%$. Dalam hal ini dijelaskan bahwa temperatur sangat berpengaruh terhadap porositas bahwa poripori batuan akan bertambah besar setelah diberikan temperatur tinggi [10].

Dari hasil uji densitas dan porositas di daerah sungai medang yang telah dilakukan menunjukan bahwa densitas batuan sangat kecil dan setelah dilakukan pemberian temperatur rendah, sedang dan tinggi densitas tidak mengalami perubahan yang besar karena dilihat dari kerapatan batuan densitas yang baik dan juga batuan tersebut sangat keras secara fisik.Sedangkan uji porositas didaerah sungai medang yang telah dilakukan menunjukan bahwa porositas batuan sangat kecil dan setelah dilakukan pemberian temperatur rendah, sedang dan tinggi hanya mengalami perubahan terbesar $0.55 \%$ pada suhu $300^{\circ} \mathrm{c}$.
Berdasarkan hasil uji densitas dan porositas didaerah sungai medang dapat dikatakan bahwa potensi di daerah mata air panas sungai medang memiliki potensi panas bumi yang lebih baik dari daerah semurup dapat dilihat dari kecil nya perubahan sifat fisik terhadap temperatur, sebab sifat fisik batuan menunjukan bahwa batuan sangat keras dan memiliki kerapatan yang baik. Batuan yang memiliki kerapatan yang baik memiliki konduktifitas termal yang baik juga, karena batuan yang baik dapat mengantarkan panas bumi yang kostanta tanpa perubahan yang besar [11].

\section{Analisis $X$-ray Diffraction (XRD)}

Karakterisasi dengan menggunakan XRD dilakukan dengan XRD PAN alytical dengan rentang nilai $2 \theta$ sebesar $20-80^{\circ}$. Penentuan kesesuaian persentase kandungan mineral batuan yang terbentuk dilakukan dengan mencocokkan setiap puncak yang muncul pada difraktogram pada nilai sudut $2 \theta$ dan $d$ tertentu hasil analisis kandungan mineral batuan yang mendominasi terdapat kesesuaian dan struktur kristal pada batuan. Hasil karakterisasi XRD pada batuan semurup dengan software High Scoreplus dapat dilihat Gambar 5.

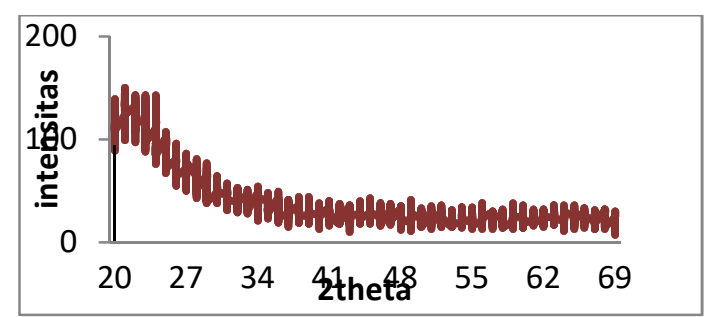

Gambar 5. Karakterisasi XRD Batuan Semurup.

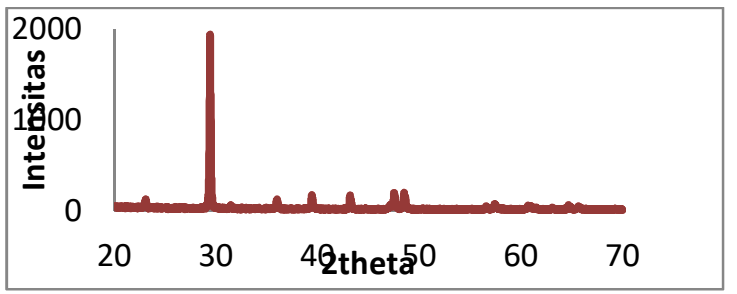

Gambar 6. Hasil Karakterisisai XRD Batuan Sungai Medang. 
Dari Gambar 5 dapat dilihat bahwa banyaknya puncak yang dihasilkan dalam mineral batuan Semurup adalah sebanyak delapan (2) buah, yaitu pada $2 \Theta$ sebesar $24,138^{\circ}, 33,153^{\circ}$ untuk mineral kandungan batuan. Dari data puncak-puncak difraksi tersebut maka puncak tertinggi dihasilkan pada sudut $2 \Theta=24,138^{\circ}$ dan nilai intensitas titik maksimum adalah 152. Komponen mineral batuan yang mendominasi adalah Calcium Carbonate dengan lambang unsur $\mathrm{CaCO}_{3}$ sebesar $94 \%$, dengan nama mineral pada batuan adalah Calcite, nilai HKL titik maksimum $\begin{array}{lllll}0 & 1 & 2 & \text { dan struktur kristal pada }\end{array}$ batuan semurup adalah Rhombohendral [12].

Hasil karakterisasi XRD pada batuan sungai medang dengan software High Scoreplus lihat pada Gambar 6. Dari Gambar 6 dapat dilihat bahwa banyaknya puncak yang dihasilkan dalam mineral batuan Sungai Medang adalah sebanyak delapan (8) buah, yaitu pada $2 \theta$ sebesar $23,023^{\circ}, 29,481^{\circ}$, $35,920^{\circ}, 39,339^{\circ}, 43,155^{\circ}, 47,606^{\circ}, 48,640^{\circ}$ dan $57,385^{\circ}$ untuk mineral kandungan batuan. Dari data puncak-puncak difraksi tersebut maka puncak tertinggi dihasilkan pada sudut $2 \theta=29,481^{\circ}$ dan nilai intensitas titik maksimum adalah 1949. Komponen mineral batuan yang mendominasi adalah Calcium Carbonatedengan lambang unsur $\mathrm{CaCO}_{3}$ sebesar $98 \%$ dengan nama mineral Calcite [13]. Nilai HKL titik maksimum 1 04 dan struktur kristal pada batuan sungai medang adalah Rhombohendral.

Berdasarkan analisis karakterisasi batuan dari semurup dan sungai medang memiliki perbedaan, pada batuan dari semurup menunjukan bahwa nilai komponen $\mathrm{CaCO}_{3}$ adalahsebesar $94 \%$ dan komponen iron oxide adalah sebesar $6 \%$ dengan struktur kristal belum terbentuk sempurna tetapi masih dalam bentuk amof, sedangkan batuan dari sungai medang menunjukan bahwa nilai komponen $\mathrm{CaCO}_{3}$ adalah sebesar $98 \%$ dan silicon $2 \%$ dengan struktur kristal sudah terbentuk sempurna seperti halnya kristal [14].

\section{KESIMPULAN}

Berdasarkan penelitian yang dilakukan, makaSifat fisis densitas batuan semurup relatif kecil sebesar $0,876 \mathrm{~g} / \mathrm{cm}^{3}$, setelah diberikan temperatur perubahan tidak signifikan hanya sebesar $0,03 \mathrm{~g} / \mathrm{cm}^{3}$ setiap penaikan temperatur, tetapi porositas batuan semurup relatif besar sebesar $12,47 \%$, yang mengalami perubahan yang signifikan pada temperatur tinggi $300^{\circ} \mathrm{C}$ sebesar $30,29 \%$ dan sifat fisis batuan sungai medang relatif kecil, setelah diberikan temperatur tidak ada yang mengalami perubahan signifikan, nilai densitas sebesar $0,9983 \mathrm{~g} / \mathrm{cm}^{3}$ yang mengalami perubahan sebesar $0,003 \mathrm{~g} / \mathrm{cm}^{3}$ setiap penaikan temperatur, Porositas sungai medang pada temperatur sebesar $0.38 \%$, yang mengalami perubahan temperatur tinggi $300^{\circ} \mathrm{C}$ sebesar $0.55 \%$. Batuan dari semurup menunjukan bahwa nilai komponen $\mathrm{CaCO}_{3}$ adalahsebesar $94 \%$, dengan struktur kristal belum terbentuk sempurna tetapi masih dalam bentuk amof, sedangkan batuan dari sungai medang menunjukan bahwa nilai komponen $\mathrm{CaCO}_{3}$ adalah sebesar $98 \%$, dengan struktur kristal sudah terbentuk sempurna seperti hal nya kristal.

\section{DAFTAR PUSTAKA}

1. Yuliandini, A. (2013). Pengaruh Formasi Batuan Terhadap Karakteristik Hidrokimia Lima Sumber Mata Air Panas Di Daerah Sapan, Pinang Awan, Kecamatan Alam Pauh Duo, Kabupaten solok Selatan. Jurnal Fisika Unand, 2(4).

2. Iosifina, et. al. (2016). Measurment and Analysis of Thermal Properties of rocks for the Compilation of Geothermal Maps of Cyprus. Renewable Energy, 418-429.

3. Putu, dkk. (2010). Studi Pengaruh Aktifasi Termal terhadap Struktur Mikro dan Porositas Zeolit Alam. Jurnal Teknik Mesin, Univeritas Udayana Bali. 
4. Ridhovi. A. P. (2016). Analisis Konduktivitas Termal dan Porositas Sinter Silika Sumber Mata Air Panas di Sapan Maluluang Kecamatan Alam Pauh Duo Kabupaten Solok Selatan. Padang. Jurnal Fisika Unand, 5(1).

5. ASTM C. (1999). Standar Test Method for Water Absorption, Bulk Density, Apparent Porosity, and Apparent Specific Gravity of Fired Whieware Product. Reapproved, 373-388.

6. Duchkov, A. D. et. al. (2014). Thermal Conductivity of the Sedimentary Cover Rocks of the West Siberian Plate in Relation to their Humidity and Porosity. Russian Geology and Geophysics, 55, 784792.

7. Edwards, L. M. et. al. (1982). Handbook of Geothermal Energy. Gulf Publishing Company. Capter 2.

8. Fathar, Q. (2013). Studi Potensi Panas Bumi Daerah Hululais Kabupaten Lebong Provinsi Bengkulu Sumatra. Jurnal Teknik, Universitas Hasanuddin

9. Fridawati, M. (2008). Analisa Struktur Kristal dari Lapisan Tipis Aluminium (Al) dengan Metode Difraksi Sinar-X (Skripsi). Yogyakarta: Universitas Sanata Dharma.

10. Khoiri, Z. (2016). Studi Anomali Bawah Permukaan Daerah Sekitar Manifestasi Air Panas.

11. Marzani, Y. (2013). Kimia Mata Air Panas Bumi untuk Pengembangan Parawisata di daerah Samboja Kabupaten Kutai Kartanegara Provinsi Kalimantan Timur. Jurnal Teknik Geologi, Universitas Negeri Kalimantan.

12. Schmidt, R. et. al. (2017). Reactivity of Geothermal Reservoir Rocks Under Temperature Conditions Found in Upper Rhine Graben (Germany). Procedia Earth and Planetary Science, 17, 881-884.

13. Telford, W. N. G. \& Sherrif, R.E. (1990), Applied Geophysics Second Edittion. New York: Cambridge University Press

14. Zhang, W., et. al. (2016). Experimental Study on the Variation of Physical and Mechanical Properties of Rock After High Temperature Treatment. Applied Thermal Engineering, 98, 1297-1304. 